\title{
Resistant hypertension with adrenal nodule: are we removing the right gland?
}

\author{
Gautam Das, Peter N Taylor, Arshiya Tabasum, L N Rao Bondugulapati', \\ Danny Parker ${ }^{2}$, Piero Baglioni, Onyebuchi E Okosieme and David Scott Coombes ${ }^{3}$
}

Department of Diabetes and Endocrinology, Prince Charles Hospital, Cwm Taf University Health Board, Merthyr Tydfil, Mid Glamorgan CF47 9DT, UK

${ }^{1}$ Department of Diabetes and Endocrinology, Maelor Hospital, Betsi Cadwaldr University Health Board, Wrexham LL13 7TD, UK

Departments of ${ }^{2}$ Histopathology, and ${ }^{3}$ Endocrine Surgery, University Hospital of Wales, Cardiff and Vale University Health Board, Cardiff CF14 4XW, UK

\author{
Correspondence \\ should be addressed \\ to G Das \\ Email \\ gautam.das@wales.nhs.uk
}

\section{Summary}

Resistant hypertension is often difficult to treat and may be associated with underlying primary aldosteronism (PA). We describe the case of an elderly gentleman who presented with severe and resistant hypertension and was found to have a left adrenal incidentaloma during evaluation but had aldosterone excess secondary to unilateral adrenal hyperplasia (UAH) of the contralateral gland, which needed surgical intervention. A 65-year-old gentleman was evaluated for uncontrolled high blood pressure (BP) in spite of taking four antihypertensive medications. The high BP was confirmed on a 24-h ambulatory reading, and further biochemical evaluation showed an elevated serum aldosterone renin ratio (ARR) (1577 pmol/l per $\mathrm{ng}$ per $\mathrm{ml}$ per $\mathrm{h}$ ). Radiological evaluation showed an adrenal nodule $(15 \mathrm{~mm}$ ) in the left adrenal gland but an adrenal vein sampling demonstrated a lateralization towards the opposite site favouring the right adrenal to be the source of excess aldosterone. A laparoscopic right adrenalectomy was performed and the histology of the gland confirmed nodular hyperplasia. Following surgery, the patient's BP improved remarkably although he remained on antihypertensives and under regular endocrine follow-up. PA remains the most common form of secondary and difficultto-treat hypertension. Investigations may reveal incidental adrenal lesions, which may not be the actual source of excess aldosterone, but UAH may be a contributor and may coexist and amenable to surgical treatment. An adrenal vein sampling should be undertaken for correct lateralization of the source, otherwise a correctable diagnosis may be missed and the incorrect adrenal gland may be removed.

\section{Learning points:}

- Severe and resistant hypertension can often be associated with underlying PA.

- ARR is an excellent screening tool in patients with suspected PA.

- Lateralization with adrenal venous sampling is essential to isolate the source and differentiate between unilateral and bilateral causes of hyperaldosteronism.

- Adrenal incidentalomas and UAH may coexist and the latter may often be the sole cause of excess aldosterone secretion.

- Decisions about adrenalectomy should be made only after integrating and interpreting radiological and biochemical test findings properly. 


\section{Background}

Patients with resistant hypertension may often have an identifiable underlying secondary cause. Primary aldosteronism (PA) is now considered to be one of the most common causes for secondary hypertension, and the relationship between aldosterone-induced sodium retention and hypertension is well established (1). Aldosterone-producing adenomas (APA) and unilateral adrenal hyperplasia (UAH) are the most established causes of PA, which, if identified, secure a specified target treatment that may potentially cure hypertension. Invasive tests like adrenal venous sampling (AVS) are usually needed to identify the correct source of excess aldosterone and to make a distinction between unilateral and bilateral disease.

\section{Case presentation}

A 65-year-old gentleman was referred to our endocrine clinic by the acute medical team for the evaluation of resistant hypertension. He initially attended the ambulatory unit with exertional symptoms that he had for a few months and was found to have elevated blood pressure (BP) (range of systolic BP was 190-200 $\mathrm{mmHg}$ and diastolic BP ranged between 100 and $110 \mathrm{mmHg}$ ) on multiple occasions. He was on titrating doses of irbesartan (300 mg once daily (OD)), doxazosin (8 $\mathrm{mg}$ twice daily (BD)), amlodipine (10 mg OD) and bisoprolol (10 mg OD) at that point. His medical background included history of iron deficiency anaemia, dyslipidemia and previous transient ischemic attacks. His other regular medications were furosemide, clopidogrel, simvastatin, fenofibrate and lansoprazole. His physical examination revealed moderate pallor, a raised BMI and elevated BP $(206 \mathrm{mmHg}$ systolic and $104 \mathrm{mmHg}$ diastolic). He did not have any audible murmurs, renal bruit or skin changes. There was no clinical evidence of Cushing's syndrome and he appeared euadrenal, euthyroid and eupituitary.

\section{Investigation}

His initial biochemical evaluation showed normal liver, kidney and thyroid functions. His serum sodium (143 mmol/l) and potassium (4.1 mmol/l) was normal as well. He was normoglycemic and his lipid profile was satisfactory. His 24-h urine-free cortisol (UFC), overnight dexamethasone suppression test and urine metanephrines were all within normal limits. His electrocardiogram (ECG) and echocardiogram were consistent with left ventricular hypertrophy. A 24-h ambulatory BP recording confirmed elevated BP ( $>90 \%$ readings above diurnal and nocturnal cut-off levels) despite treatment. An ultrasound with colour Doppler showed a normal appearance of kidneys with normal calibre of the renal arteries. He was commenced on a trial dose of spironolactone $25 \mathrm{mg}$ OD initially, which improved his BP dramatically, and after 2-3 weeks of treatment with spironolactone and dose titration of other antihypertensives, his BP improved to an average of $\sim 150 / 90 \mathrm{mmHg}$.

This prompted a few change with his antihypertensive combinations. As he responded well to spironolactone, it was suspected that he might have PA, which could explain his resistant hypertension. His $\beta$ blocker and spironolactone was stopped and he was commenced on diltiazem. Over the next 4 weeks he was followed regularly in the ambulatory unit for the monitoring of BP and dose titration of his antihypertensive combinations. After a washout period of 4 weeks, an aldosterone renin ratio (ARR) was organized, which showed an elevated value of $1577 \mathrm{pmol} / \mathrm{l}$ per $\mathrm{ng}$ per $\mathrm{ml}$ per $\mathrm{h}$ (aldosterone, $410 \mathrm{pmol} / \mathrm{l}$; plasma renin activity, $0.26 \mathrm{ng} / \mathrm{ml}$ per $\mathrm{h}$ ), normal cut-off of ARR, $750 \mathrm{pmol} / \mathrm{l}$ per ng per $\mathrm{ml}$ per $\mathrm{h}$ (1). This was followed with an magnetic resonance imaging (MRI) of his adrenals, which showed a $15 \mathrm{~mm}$ nodule in the left adrenal that had a benign appearance and the right gland was reported to be normal (Fig. 1).

As PA was evident due to an elevated ARR, he was referred to a tertiary centre for AVS, which confirmed

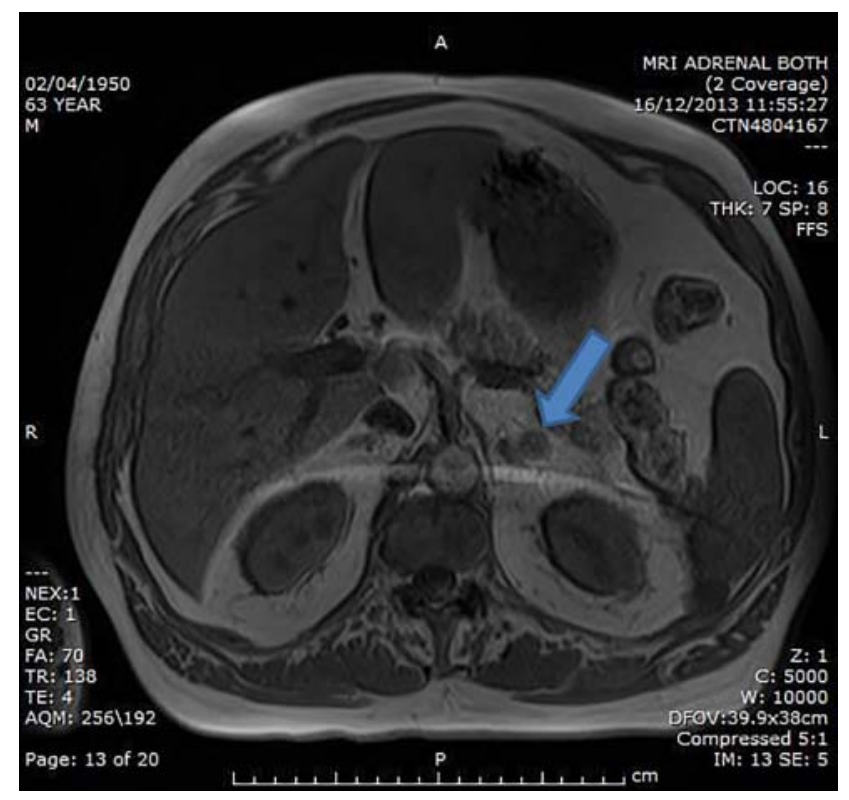

Figure 1

Left adrenal nodule on MRI scan. 
Table 1 Basal and post-synacthen aldosterone and cortisol levels from adrenal vein sampling.

\begin{tabular}{|c|c|c|c|c|}
\hline \multirow{2}{*}{$\begin{array}{l}\text { Site of } \\
\text { venous } \\
\text { sampling }\end{array}$} & \multicolumn{2}{|c|}{ Basal } & \multicolumn{2}{|c|}{5 min (post-synacthen) } \\
\hline & $\begin{array}{l}\text { Cortisol } \\
\text { (nmol/l) }\end{array}$ & $\begin{array}{l}\text { Aldosterone } \\
(\mathrm{pmol} / \mathrm{l})\end{array}$ & $\begin{array}{l}\text { Cortisol } \\
(\mathrm{nmol} / \mathrm{l})\end{array}$ & $\begin{array}{c}\text { Aldosterone } \\
\text { (pmol/l) }\end{array}$ \\
\hline Peripheral & 481 & 231 & 479 & 439 \\
\hline Right adrenal & 4957 & 25248 & 12458 & 251335 \\
\hline Left adrenal & 5230 & 1968 & 5152 & 10645 \\
\hline
\end{tabular}

a very high basal and $5 \mathrm{~min}$ aldosterone levels after synacthen stimulation from his right adrenal vein in keeping with a diagnosis of PA, but it was from the side opposite to the adrenal nodule that was visible on MRI (Tables 1 and 2).

\section{Treatment}

The patient's clinical profile, radiology and endocrine tests were discussed in the endocrine multidisciplinary meeting and he was recommended for a laparoscopic right adrenalectomy, which was successfully completed by the endocrine surgeons a couple of months later. The morphology of the gland showed gross enlargement (40 g) and the histology was consistent with adrenocortical nodular hyperplasia (Fig. 2). The left gland with the nodule was left alone and was considered to be an incidentaloma.

\section{Outcome and follow-up}

The patient recovered very well in the post-operative period with minimal scar at the operative site. He is currently 4 months post-op and is under regular endocrinology follow-up. His BP currently averages $145 / 80 \mathrm{mmHg}$ but he still remains on three antihypertensives (diltiazem $60 \mathrm{mg}$ BD, irbesartan $300 \mathrm{mg}$ OD and amlodipine $10 \mathrm{mg}$ OD), which are gradually being titrated down guided by his BP response. His post-operative urea, creatinine and electrolytes (U/Es) are normal and the ARR has lowered to normal range of $320.5 \mathrm{pmol} / \mathrm{l}$ per $\mathrm{ng}$ per $\mathrm{ml}$ per $\mathrm{h}$ (aldosterone, $125 \mathrm{pmol} / \mathrm{l}$; plasma renin activity $0.39 \mathrm{ng} / \mathrm{ml}$ per $\mathrm{h}$ ) as well.

\section{Discussion}

Adrenal nodules are often inadvertently discovered with imaging studies while evaluating patients for severe and resistant hypertension. The detection of such lesions should prompt biochemical evaluation for exclusion of hypercortisolism, aldosteronism and the presence of a phaechromocytoma. In patients with moderate to severe resistant hypertension (with or without hypokalemia) and in hypertension with incidentalomas, the prevalence of PA is high and requires appropriate screening and definitive tests to establish the diagnosis (1). An APA and bilateral idiopathic hyperplasia (BIH) accounts for $95 \%$ of all cases of PA, but rare subtypes like UAH (2\%), glucocorticoid remedial aldosteronism $(<1 \%)$ and pure aldosterone-producing adrenocortical carcinoma $(<1 \%)$ have also been identified (2).

Although ARR remains an excellent and reliable mean for screening for PA, confirmatory tests like lack of suppression of aldosterone levels after salt loading have been recommended for exclusion of false positive cases (1). We had a high index of suspicion for positive case detection of PA in our patient due to his clinical profile, MRI findings, ARR of twice above the cut-off value and partial response to spironolactone for which no further additional confirmatory tests were undertaken.

It is crucial to make a distinction between unilateral and bilateral aldosterone hypersecretion in patients with PA owing to the fact that unilateral hypersecretion may be cured with adrenalectomy, whereas in bilateral hypersecretion a mineralocorticoid receptor antagonist is usually the treatment of choice (3). A CT/MRI of the adrenal gland may reveal nodules or masses, but the caveat in using radiology alone for detection of APA is that small adenomas may be missed or may be labelled incorrectly and many adrenal adenomas may be non-functioning as in our patient (4). CT alone may often demonstrate unilateral nodules in patients with bilateral disease, which can be misleading. Moreover, adrenal hyperplasia may be visible or may appear normal on adrenal CT scan and these results are inaccurate and inconclusive. Interpretations of tests based on imaging studies alone can be confounding and equivocal, leading to improper decision making.

AVS is highly effective in detecting lateralization of aldosterone secretion and it is 95\% sensitive and 100\%

Table 2 Results of aldosterone: cortisol ratio from adrenal vein sampling.

\section{Site of venous sampling}

Peripheral

Right adrenal

Left adrenal

\begin{tabular}{|c|c|}
\hline Basal & $5 \mathrm{~min}$ \\
\hline 0.5 & 0.9 \\
\hline 5.1 & 20.2 \\
\hline 0.4 & 2.1 \\
\hline
\end{tabular}




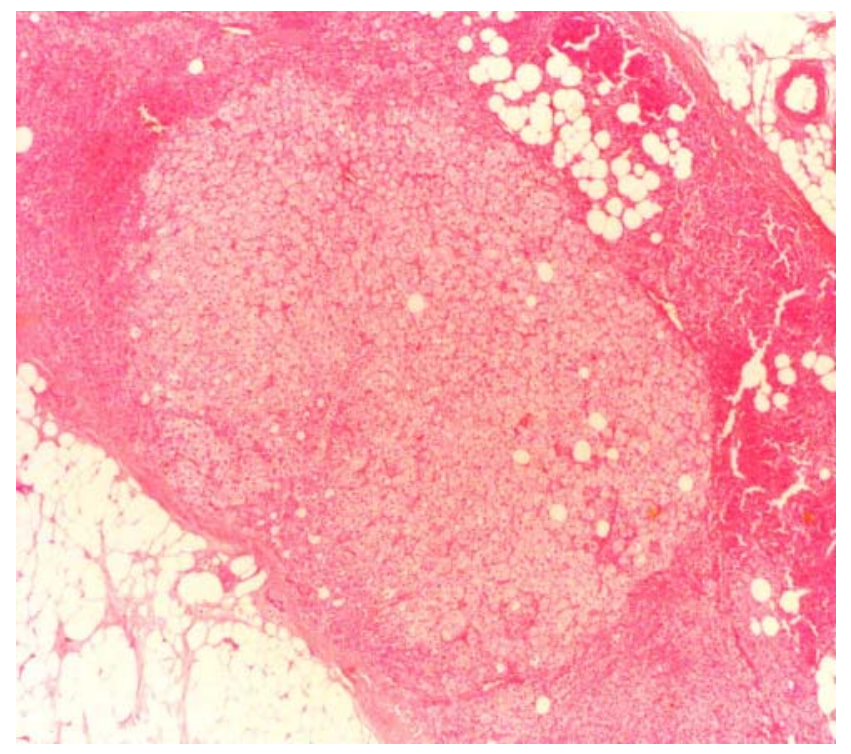

Figure 2

Histology of right adrenal gland showing adrenocortical nodular hyperplasia.

specific in detecting unilateral aldosterone hypersecretion (5). Isolated reliance on CT/MRI to determine a treatment strategy may lead to inappropriate adrenalectomy in $14.6 \%$ patients, inappropriate exclusion of adrenalectomy in $19.1 \%$ and adrenalectomy on the inappropriate side in $3.9 \%$ cases (6). In our patient the AVS proved to be an effective tool in demonstrating a unilateral dominant disease that was on the opposite side of the adrenal nodule, but it does not always preclude the possibility of the contralateral gland being free from hyperplasia (1). In the absence of such lateralization the incidental nodule could have been mistaken for an APA, leading to the removal of the wrong gland.

Unilateral adrenalectomy is curative in patients with APA and UAH and there is strong evidence to suggest that lowering of BP and serum aldosterone levels improves cardiac and cerebrovascular outcomes (7). Although spironolactone improved the BP in our patient initially, it was still inadequately controlled, which posed an increased risk for long-term cardiovascular risk and morbidity. Following an informed discussion, our patient was willing to pursue a treatment option that would offer a definitive cure and optimal outcome with regards to his BP management. Following adrenalectomy, his BPs have reduced and the number of medications has lessened. Studies have reported a normalization or amelioration of $\mathrm{BP}$ in $80 \%$ of cases at a mean follow-up of 2 years (8) (9), but it will be difficult to predict whether patients will be entirely tablet free as, although important, resolution of hypertension by itself is insufficient to assess the cure of PA as a multitude of other factors may contribute to persistently elevated BP. Therefore, BP alone can be a surrogate marker for determining cure but the gold standard would be normalization of biochemical parameters like electrolytes and ARR (3).

Finally, the histology of the gland in our patient was consistent with adrenocortical hyperplasia, which is an important cause for PA. Although under-reported in the past, several studies have reported a high prevalence of UAH in operated cases (10). Several diseases like unilateral multiple adrenocortical micronodules, nodular adrenal hyperplasia, non-single unilateral adenomas and unilateral dominant nodule or diffuse hyperplasia comes under the ambit of UAH and forms an important group of unilateral and surgically curable diseases (3).

In conclusion, adrenal incidentalomas identified during endocrine evaluation of resistant hypertension may not be the source of hyperaldosteronism as lateralization studies with AVS may identify co-existing pathologies like UAH, which may not be readily identified radiologically. Careful considerations should be made while interpreting radiological and biochemical tests to avoid incorrect surgical decisions and to ensure that the right gland is removed.

\section{Declaration of interest}

The authors declare that there is no conflict of interest that could be perceived as prejudicing the impartiality of the research reported.

\section{Funding}

This research did not receive any specific grant from any funding agency in the public, commercial or not-for-profit sector.

\section{Patient consent}

Written informed consent has been obtained from the patient for publication of the case report.

\section{Author contribution statement}

G Das was the responsible endocrinologist for this patient and he conceived, drafted and reviewed the article. P N Taylor, A Tabasum and L N Rao Bondugulapati were involved in the clinical care of the patient and have arranged relevant investigations at different periods. D Parker was responsible for the histology reporting post-adrenalectomy. O E Okosieme and $\mathrm{P}$ Baglioni reviewed the final draft of the article and provided valuable comments. D Scott Coombes was the endocrine surgeon responsible for this patient's adrenalectomy. 


\section{Reference}

1 Funder JW, Carey RM, Fardella C, Gomez-Sanchez CE, Mantero F, Stowasser M, Young WF, Jr \& Montori VM 2008 Case detection, diagnosis, and treatment of patients with primary aldosteronism: an endocrine society clinical practice guideline. Journal of Clinical Endocrinology and Metabolism 93 3266-3281. (doi:10.1210/jc.2008-0104)

2 Young WF 2007 Primary aldosteronism: renaissance of a syndrome. Clinical Endocrinology 66 607-618. (doi:10.1111/j.1365-2265.2007. 02775.x)

3 Iacobone M, Citton M, Giovanni V, Boetto R, Bonadio I, Tropera S, Mantero F, Rossi GP, Fassina A, Nitti D et al. 2012 Unilateral adrenal hyperplasia: a novel cause of surgically correctable primary hyperaldosteronism. Surgery 152 1248-1255. (doi:10.1016/j.surg.2012.08.042)

4 Fujiwara M, Murao K, Imachi H, Yoshida K, Muraoka T, Ohyma T, Kushida Y, Haba R, Kakehi Y \& Ishida T 2010 Misdiagnosis of two cases of primary aldosteronism owing to failure of computed tomography to detect adrenal micro adenoma. American Journal of the Medical Sciences 340 335-337. (doi:10.1097/MAJ.0b013e3181e95587)

5 Young WF, Stanson AW, Thompson GB, Grant CS, Farley DR \& Van Heerden JA 2004 Role of adrenal venous sampling in primary aldosteronism. Surgery 136 1227-1235. (doi:10.1016/j.surg. 2004.06.051)
6 Kempers MJ, Lenders JW, van Outheusden L, van der Wilt GJ, Schultze Kool LJ, Hermus AR \& Denium J 2009 Systematic review: diagnostic procedures to differentiate unilateral from bilateral adrenal abnormality in primary aldosteronism. Annals of Internal Medicine 151 329-337. (doi:10.7326/0003-4819-151-5-200909010-00007)

7 Rossi GP, Sacchetto A, Visentin P, Canali C, Graniero GR, Palatini P \& Pessina AC 1996 Changes in left ventricular anatomy and function in hypertension and primary aldosteronism. Hypertension 27 1039-1045. (doi:10.1161/01.HYP.27.5.1039)

8 Novitsky Y, Kercher K, Rosen M, Cobb WS, Jyothinagaram S \& Heniford BT 2005 Clinical outcomes of laparoscopic adrenalectomy for lateralizing nodular hyperplasia. Surgery 138 1009-1017. (doi:10.1016/j.surg.2005.09.027)

9 Lumachi F, Ermani M, Basso SM, Armanini D, Iacobone M \& Favia G 2005 Long term results of adrenalectomy in patients with aldosterone producing adenomas: multivariate analysis of factors affecting unresolved hypertension and review of the literature. American Surgeon 71 864-869.

10 Goh BK, Tan YH, Chang KT, Eng PH, Yip SK \& Cheng CW 2007 Primary hyperaldosteronism secondary to unilateral adrenal hyperplasia: an unusual cause of surgically correctable hypertension. A review of 30 cases. World Journal of Surgery 31 72-79. (doi:10.1007/ s00268-005-0594-8)

Received in final form 14 August 2015 Accepted 28 August 2015 